\title{
Our Preference for Central Venous Intervention in Patients with Haematologic Malignancies Following Intensive Care Unit
}

\section{Yoğun bakım ünitesinde takip ettiğimiz hematolojik malignensi hastalarında santral venöz girişim bölgesi tercihlerimiz}

\author{
Süheyla Ünver, Arif Timuroğlu, Saadet Menteş, Sinem Gevenkiriş, Tuğba Aşkın
}

Doktor Abdurrahman Yurtaslan Ankara Onkoloji Eğitim ve Araştırma Hastanesi, Ankara, Türkiye

\section{ÖZET}

GÍRIŞ ve AMAÇ: Kanser hastalarında damar yolu erişimi hayati önem taşıyan bir konudur. Özellikle santral venöz basınç monitorizasyonu, intravenöz kemoterapi, çoklu antimikrobiyal tedavi, laboratuvar inceleme için kan örneği alma, uzun süreli beslenme, kan ve kan ürünü transfüzyonu gibi işlemlere kolaylık sağlaması sebebiyle sıklıkla ihtiyaç duyulur. Ancak bu grup hastalarda santral venöz kateterizasyon girişimi ciddi komplikasyon riski içerir. Kateter ilişkili enfeksiyonlar ve kanama problemleri bu grup hastalarda önemli bir sorun oluşturmaktadır. Santral venöz kateter uygulama bölgesine karar vermek ve yönetmek hematolojik malignensili hastalar için önem arz etmektedir. Biz de bu çalışmada son bir yıl içinde anestezi yoğun bakım ünitesinde takip ettiğimiz hematolojik malignensili hastalardaki santral venöz kateter girişimlerimizi uygulama bölgesi tercihimiz ve ortaya çıkan komplikasyon oranları açısından retrospektif olarak incelemeyi amaçladık.

YÖNTEM ve GEREÇLER: Bir yıl içerisinde yoğun bakımda santral ven kateteri yerleştirilmiş hematolojik malignensi olan 40 hasta retrospektif olarak değerlendirildi. Hastalar girişim yeri, kanama, kateter enfeksiyonu ve kateterin kalış günü açısından incelendi. Veriler bir kişisel bilgisayarda SPSS 24.0 versiyon ile frekans, çapraz tablolar, mann whitney-u analizleri ile değerlendirildi.

BULGULAR: Takılan kateterlerin 16 tanesinin internal juguler ven/subklaviyen ven (\%40), 24 tanesinin ise femoral ven (\%60) olarak tercih edildiği tespit edildi. Takılan kateterlerin üç tanesindeki üreme kateter ilişkili enfeksiyon olarak kabul edildi, bu kateterlerin yerleşim yeri femoral dışı girişimdi. Femoral dışı girişim yapılan bir hastada kanama komplikasyonu görüldü. Femoral kateterlerin ortalama kalış süresi 5,8 gün internal juguler ven/subklaviyen venden yerleştirilen kateterlerin ortalama kalış süresi 9,3 gün olarak tespit edildi.

TARTIŞMA ve SONUÇ: Hematolojik maligniteli ve yoğun bakım endikasyonu olmuş hastalarda, gerekli asepsi kurallarına uyulduğunda femoral kateterizasyonun enfeksiyon açısından da güvenle tercih edilebileceğini, hemostaz açisından uygun koşullar oluştuğunda subklaviyen veya internal juguler vene geçilmesini tavsiye ediyoruz.

Anahtar Kelimeler: Kateterizasyon, santral venöz, kateter ilişkili enfeksiyonlar, hematolojik malignensiler

\begin{abstract}
INTRODUCTION: Intravenous access in cancer patients is a matter of vital importance. In particular, central venous pressure monitoring, intravenous chemotherapy, multiple antimicrobial treatment, laboratory review of blood sample, long-term nutrition, blood and blood product transfusion as a convenience for such operations are often needed. However, in this group of patients, the central venous catheterization attempt involves a serious complication risk. Catheter-related infections and bleeding problems are a major problem in this group of patients. The decision and management of the central venous catheter is important for patients with haematological malignancies. In this study, we aimed to investigate the use of Central venous catheter interventions in hematologic malignancies patients who have followed anaesthesia intensive care unit in the last year and retrospectively in terms of the complication rate of our choice in the region. METHODS: In one year, 40 patients with haematological malignancies with a central venous catheter were retrospectively evaluated. The patients were examined in terms of location, bleeding, catheter infection and the day of the catheterization. The data were analysed with SPSS 24.0 version on a personal computer. RESULTS: 16 of the implanted catheters were preferred as internal jugular vein/subclavian vein (40\%) and 24 as femoral vein $(60 \%)$. Three of the implanted catheters were associated with catheter infection, the placement of these catheters was a non-femoral attempt. A patient with a non-femoral procedure had bleeding complication.
\end{abstract}


The mean duration of the femoral catheters was 5.8 days and the mean duration of the catheters placed from the internal jugular vein/subclavian vein was 9.3 days.

DISCUSSION and CONCLUSION: In patients with hematologic malignancy and intensive care indications, we recommend that femoral catheterization be safely chosen in terms of infection if the required asepsis rules are followed, and subclavian or internal juguler vene should be recommended when appropriate conditions are established for haemostasis.

Keywords: Catheterization, Central Venous, catheter related infections, haematologic malignancies.

\section{GíRiş}

Kanser hastalarında damar yolu erişimi hayati önem taşıyan bir konudur. Santral venöz kateter hematoloji ve onkoloji hastalarının yoğun bakım tedavisinde de önemli yer tutmaktadır. Özellikle santral venöz basınç monitorizasyonu, intravenöz kemoterapi, çoklu antimikrobiyal tedavi, laboratuvar inceleme için kan örneği alma, uzun süreli beslenme, kan ve kan ürünü transfüzyonu gibi işlemlere kolaylık sağlaması sebebiyle sıklıkla ihtiyaç duyulur (1). Ancak bu grup hastalarda santral venöz kateterizasyon girişimi ciddi komplikasyon riski içerir. Uygulanan tedaviler ve hastalığın doğal seyri gereği sıklıkla anemi, trombositopeni, koagülopati ve nötropeni görülmektedir. Kanama girişimin en öncelikli komplikasyonudur. Kateter girişim yerinden sızıntı ve cilt altı kanama şeklinde hafif ve önemsiz olabileceği gibi hemomediastinum veya hemotoraks gibi hayatı tehdit edecek kadar ciddi de olabilir. Bir diğer sorun da kateter ilişkili enfeksiyonlardır. Santral venöz kateter uygulama bölgesine karar vermek ve yönetmek hematolojik malignensili hastalar için önem arz etmektedir. Biz de bu çalışmada son bir yıl içinde anestezi yoğun bakım ünitesinde takip ettiğimiz hematolojik malignensili hastalardaki santral venöz kateter girişimlerimizi uygulama bölgesi tercihimiz ve ortaya çıkan komplikasyon oranları açısından retrospektif olarak incelemeyi amaçladık.

\section{YÖNTEM ve GEREÇ}

Ocak 2017 ile Ocak 2018 tarihleri arasında yoğun bakımda santral ven kateteri yerleştirilmiş hematolojik malignensi olan 40 hasta retrospektif olarak değerlendirildi.
Hastalar demografik veriler, girişim yeri, kanama, kateter enfeksiyonu ve kateterin kalış günü açısından incelendi. Kliniğimiz protokolü gereği olarak tüm invaziv işlemler bir uzman doktor veya uzman doktor eşliğinde bir araştırma görevlisi tarafından gerçekleştirildi. Kateterler Seldinger yöntemi ile maksimum sterilizasyon kurallarına uyularak, steril eldiven önlük, bone maske eşliğinde yerleştirildi. Kanama komplikasyonlarını değerlendirmek amaciyla hastaların girişim öncesi trombosit sayısı, INR değeri ve aktive parsiyel tromboplastin zamanı (aPTT) kaydedildi. Kateter malpozisyonu akciğer grafilerinden, komplikasyonlar klinik seyirlerden kontrol edildi. Ateşi çıkan her hastanın kateter ve perifer kan kültürü eş zamanlı olarak alındı. Kateter ilişkili enfeksiyon olarak kabul edilen vakalar enfeksiyon kontrol komitesi kayıtları ile tespit edildi. Kateter enfeksiyonu olarak kabul edilenler gerekli kan ürünü replasmanı yapılarak çekildi. Veriler bir kişisel bilgisayarda SPSS 24.0 versiyon ile frekans, çapraz tablolar, mann whitney-u analizleri ile değerlendirildi.

\section{BULGULAR}

İncelenen olguların yaş ortalaması $56( \pm 16)$ yıl, hastaların 18'i kadın, 22'si erkek idi. Hastaların ortalama trombosit sayıs1 55.000 ( \pm 49.000) $/ \mathrm{mm}^{3}$, INR 1.50 ( \pm 0.57), aPTT 32 saniye $( \pm 8.9)$, fibrinojen $346( \pm 151) \mathrm{mg} / \mathrm{dL}$ idi (Tablo 1). Tak1lan kateterlerin 16 tanesinin internal juguler ven/subklaviyen ven (IJJV/SCV) (\%40), 24 tanesinin ise femoral ven (\%60) olarak tercih edildiği tespit edildi. Takılan kateterlerin üç tanesindeki üreme kateter ilişkili enfeksiyon olarak kabul edildi, 
bu kateterlerin yerleşim yeri İJV/SCV idi (Tablo 2). Femoral kateterizasyon yapılan hastaların ortalama trombosit sayıs1 $41.000 / \mathrm{mm}^{3}$ iken, femoral dişı kateterizasyon yapılan hastaların trombosit sayıs $75.000 / \mathrm{mm}^{3}$ olduğu tespit edildi. İJV girişim yapılan 39.000 $/ \mathrm{mm}^{3}$ trombosit sayıl1 bir hastada ultrason eşliğinde uygulanan girişim sonrası hematom gözlemlendi. Hiçbir hastada hemopnömotoraks ya da kateter malpozisyonu görülmedi.

\section{TARTIŞMA}

Hematolojik maligniteli hastalarda santral venöz girişimlerin iki önemli sorunu vardır. Birinci sorun bu grup hastaların koagülopati sorunu olmasıdır. Hemostaz bozukluklarına yol açan sebepler aynı zamanda ciddi immunsupreyona da neden olmaktadır. Bu da hematolojik maligniteli hastalarda santral venöz girişimlerin ikinci büyük sorunu olan kateter ilişkili enfeksiyon kontrolünü zorlaştırmaktadır.

Tecrübeli ellerde geçici santral venöz kateter yerleştirilmesi hemostaz sorunu olan hastalarda bile güvenli bir yöntem olup, kanama komplikasyonu düşüktür (2). Ancak yine de kanama komplikasyonu birçok çalışmalarda \%3-20 düzeylerindedir (3). Kanama ve hematom ile ilişki en önemli klinik faktör düşük trombosit düzeyidir. Hatta hemostaz problemi olan hastalarda kanama komplikasyonu ile ilişkili tek klinik faktörün trombositopeni olduğunu bildiren araştırmacılar mevcuttur. Doerfler, santral venöz kateter yerleştirilen ve minör kanama komplikasyonu gelişen hastaların trombosit değerlerinin $\quad 6000-37000 \quad / \mathrm{mm}^{3}$ (ortalama $22000 / \mathrm{mm}^{3}$ ) arasında olduğunu bildirmiştir (4). Birden fazla girişim, girişimin İJV yoluyla olması, başarısız kateterizasyon, yüksek INR değeri, düşük trombosit değeri de hematom ve kanama için predispozan faktörler olarak bildirilmiştir (3). Hematolojik malignitesi olup yoğun bakıma kabul edilen hastalarda kemik iliği depresyonu nedeni ile hemostaz problemleri ön plandadır. Bu da santral venöz yol için tercih edilecek bölgeyi zorlaştırmaktadır. Biz de geçmiş tecrübelerimizdeki tercihlerimize baktığımızda femoral kateter tercih oranımızın \%60 olduğunu gördük. Bir hastamızda girişim yeri olarak femoral dışı yol tercih etmemize ve girişimin ultrason eşliğinde gerçekleştirilmesine rağmen hematom oluştu. $\mathrm{Bu}$ hastanın trombosit sayıs $39000 \mathrm{~mm}^{3}$ idi. Takiplerinde hematom rezorbe olarak dağıldı. Santral venöz kateterler ile ilgili ikinci önemli çekince de kateter ilişkili enfeksiyonlardır. Hematolojik malignensili hastalarda yapılan santral venöz kateterizasyon işlemleri, kullanilan kemoterapotikler ve hatta beraberinde steroid tedavisinin de olmas1 nedeniyle artmış kateter enfeksiyon oranlarına neden olabilir.

Kateter ilişkili enfeksiyonlar incelendiğinde femoral venöz kateterizasyona bağlı artmış enfeksiyon hızları, femoral dışı girişime oranla daha yüksek kabul edilmesine rağmen, femoral girişimin bu açıdan yüksek riske sahip olmadığını gösteren çalışmalar da mevcuttur. Paul E. Marik ve ark.'in yaptığ 1 bir meta analizde internal juguler, subklaviyen ve femoral venöz girişimler incelenmiş ve kateter ilişkili enfeksiyon hızları arasında fark olmadığ1 gösterilmiştir (5). Bizim çalışmamızda da kateter ilişkili enfeksiyon kabul edilen vakaların tamamı femoral dışı girişim neticesinde gerçekleşmiştir. Ancak oluşan kateter enfeksiyonlarının femoral dışı girişim bölgesinde gerçekleşmesine sebep olarak, yerleştirdiğimiz femoral kateterlerin kalış süresinin diğer gruba göre daha kısa olması da olabileceğini düşünmekteyiz. Girişim esnasında steril örtü, önlük, maske, eldiven kullanımının artması, el hijyenine dikkat edilmesi, cilt dezenfeksiyonu için klorheksidin kullanımı, ultrason rehberliğinde işlem yapılması sonucunda kateter ilişkili enfeksiyon hızı y1llar içerisinde giderek azalmaktadır (6). Galler Sağlık Hizmetleri İlişkili Enfeksiyon Programı da girişim yerleri 
arasında enfeksiyon hızı açısından anlamlı fark olmadığını belirtmektedir (7). Biz, femoral santral venöz kateteri ortalama 5,8 gün hastada kullandığımızı gördük. Hastanın hemostaz verileri düzeldiği zaman, hala kateterizasyon ihtiyacı mevcut ise femoral dışı santral kateterizasyona geçtik.

Yoğun bakım ünitesinde santral venöz kateterizasyon endikasyonu olduğunda oluşabilecek komplikasyonlardan kaçınmak ve hasta için en doğru yeri seçmek zor bir karar olmakla beraber hematolojik maligniteli hastalarda çok daha önemlidir. Biz de klinik deneyimlerimizle geçmişte yaptığımız tercihlerimize baktığımızda hematolojik maligniteli hastalarda femoral kateterizasyonu daha sıklıkla tercih ettiğimizi gördük ancak femoral venöz kateteri femoral dışı kateterlere göre daha kısa süre tuttuğumuzu gördük. Güncel literatürde femoral kateterizasyonun enfeksiyon açısından güvenli olduğu yönünde yayınlar mevcuttur.

Sonuç olarak biz; hematolojik maligniteli ve yoğun bakım endikasyonu olmuş hastalarda, gerekli asepsi kurallarına uyulduğunda femoral kateterizasyonun enfeksiyon açısından da güvenle tercih edilebileceğini, hemostaz açısından uygun koşullar oluştuğunda subklaviyen veya internal juguler vene geçilmesini tavsiye ediyoruz.

Tablo 1. Hastaların demografik verileri, laboratuvar bulguları

\begin{tabular}{|l|c|c|c|}
\hline & İJV/SC & Femoral & $\mathrm{p}$ \\
\hline Yaş (yll) & $50,0( \pm 18,3)$ & $59,9( \pm 13,6)$ & 0,06 \\
\hline Cinsiyet (n) (E/K) & $(8) /(8)$ & $(14) /(10)$ & 0,62 \\
\hline Trombosit $\left(\mathrm{mm}^{3}\right)$ & $75810( \pm 55443)$ & $41170( \pm 41442)$ & 0,03 \\
\hline INR & & & \\
\hline Fibrinojen (mg/dL) & $306( \pm 115)$ & $373( \pm 168)$ & 0,18 \\
\hline aPTT* (saniye) & $29( \pm 7)$ & $35( \pm 9)$ & 0,049 \\
\hline $\begin{array}{l}\text { p }<0,05 \text { anlamll kabul edildi. } n \text {; hasta sayısı olarak verildi, veriler ortalama } \\
\text { değerlerdir, parantez içerisindeki veriler }( \pm) \text { standart sapma değerleridir. }\end{array}$ & \\
\hline
\end{tabular}

\footnotetext{
* İnternal juguler ven/subklaviyen ven

$\dagger$ İnternational normalized ratio

$\$$ Aktive parsiyel tromboplastin zamanı

Adress for correspondence: Arif Timuroğlu, Dr. Abdurrahman Yurtaslan Ankara Onkoloji Eğit. ve Araş. Hastanesi Ankara, Türkiye

e-mail: ariftimuroglu@yahoo.com

Available at www.actaoncologicaturcica.com

Copyright $\odot$ Ankara Onkoloji Hastanesi
} 
Tablo 2. Komplikasyonlar ve kateter kalıș süresi

\begin{tabular}{|l|c|c|c|}
\hline & IJV/SC $^{1}$ & Femoral & $\mathrm{p}$ \\
\hline Kanama komplikasyonu (n) & 1 & - & 0,40 \\
\hline Kateter enfeksiyonu (n) & 3 & - & 0,06 \\
\hline Kateter kalış süresi, gün & $9,3(2-28)$ & $5,8(2-14)$ & 0,03 \\
\hline
\end{tabular}

$\mathrm{p}<0,05$ anlamlı kabul edildi. $\mathrm{n}$; hasta sayısı olarak verildi, parantez içerisindeki veriler minimum-maksimum değerlerdir

${ }^{1}$ İnternal juguler ven/subklaviyen ven

\section{REFERANSLAR}

1. Schwarz RE, Groeger JS, Coit DG. Subcutaneously implanted central venous access devices in cancer patients: a prospective analysis. Cancer 1997; 79: 163545

2. Foster PF, Moore LR, Sankary HN, Hart ME, Ashmann MK, Williams JW. Central venous catheterization in patients with coagulopathy. Arch Surg 1992;127(3):273-275.

3. Fisher NC, Mutimer DJ. Central venous cannulation in patients with liver disease and coagulopathy-a prospective audit. Intensive Care Med 1999;25:481-48

4. Doerfler ME, Kaufman B, Goldenberg AS. Central venous catheter placement in patients with disorders of hemostasis. Chest 1996;110(1):185-188

5. Paul E. Marik, Mark Flemmer, Wendy Harrison, The risk of catheter-related bloodstream infection with femoral venous catheters as compared to subclavian and internal jugular venous catheters: A systematic review of the literature and meta-analysis. Crit Care Med. 2012 Aug;40(8):2479-85

6. O'GradyAlexander, Burns LA et al: CDC Guidelines for the Prevention of intravascular catheter-related infections. Centers for Disease Control and Prevention. Available at: http://www.cdc.gov/hicpac/BSI/BSIguidelines-2011.html 2011 Accessed September 29, 2011.

7. Welsh Healthcare Associate Infection Programme Critical care annual report. 01/09/2018.http://www2.nphs.wales.nhs.uk:8080/WHA IPDocs.nsf/3dc04669c9e1eaa880257062003b246b/e4ff 93f1d0620dbc80257bc9003cffe5/\$FILE/All\%20Wales \%20Critical\%20Care\%20CVC\%20\&\%20VAP\%20Rep ort\%202012.pdf 